\title{
DIE HOORDER EN DIE PREDIKING - AAN \\ DIE HAND VAN DIE VRAELYSTE
}

\section{Begrensing}

Die volgende uitgangspunte word vir hierdie onderwerp aanvaar. Dit word deurgaans veronderstel.

1.1. Die Heilige Gees lei die prediker en die hoorder in die voorbereiding en aanhoor van die prediking. Die Heilige Gees werk ook deur die prediking in die hart van die hoorder. (Rom. $10: 17$ ).

1.2. Die prediker staan in ' $n$ bepaalde amp en die amp het gesag. Elke predikant het ook sy eie persoonlikheid, preekstyl, talente, werkwyse en aanbieding van sy preek.

1.3. Die hoorder het ook 'n roeping t.o.v. die prediking: hy moet onbevange luister en ook voorbidding doen om die leiding van die Gees.

1.4. Die Evangelie is nie na die mens nie. Die "skandalon" mag nooit uit die prediking weggeneem word nie.

1.5. Beide hoorder en prediker is sondaars. Hierdie vyf uitgangspunte word deurgaans veronderstel. Die begrensing van die onderwerp beteken dus dat ons as predikante gaan luister deur die ore van die lidmaat wat elke Sondag in die kerk sit. En dat ons na die dominee gaan kyk deur die oë van die broeder in die kerkbank voor ons - soos dit in die vraelys en antwoorde voor ons ontvou is.

\section{Enkele formele gegewens oor die vraelys}

2.1. Honderd vraelyste is aan geselekteerde hoorders dwarsoor die land gestuur.

2.2. Almal was toegewyde kerkmense - mense wat die kerk in die reël tweemaal per Sondag besoek. Lidmate kon die lys anoniem voltooi.

2.3. Van die 100 vraelyste is 47 terug ontvang.

2.4. Uit die 47 was dit duidelik dat net twee die vraelys volgens die ,ideaalbeeld" beantwoord het - d.w.s. soos hy gedink het dit moet wees, en nie soos hy dink dit is nie.

2.5. Die vraelys is soos volg ingedeel:

2.5.1. Inhoudelik.

2.5.2. Stofkeuse.

2.5.3. Aktualiteit van die preek.

2.5.4. Formeel.

2.5.5. Wenke van hoorders.

Ek volg ook hierdie indeling in hierdie voordrag.

3. Inhoudelik - d.w.s. vrae oor die inhoud van die preek

3.1. Vyf vrae is hier gestel.

3.1.1. Wat verwag $u$ as hoorder van die preek?

3.1.2. Hoe beoordeel $u$ die preke wat $u$ hoor in die lig van wat $u$ van 'n preek verwag? 
3.1.3. Kry u die indruk dat daar erns gemaak is met die studie en voorbereiding van die preek?

3.1.4. Word die N.T. belig vanuit die O.T. of is daar 'n gelykskakeling tussen die O.T.-situasie en ons situasie.

3.1.5. Indien u sonder reserwes met dominees kan praat, watter raad sou u hulle wou gee?

3.2. Wat verwag die hoorders van die preek en hoe beoordeel hulle dit?

3.2.1. Aktualiteit. 'n Sterk lyn wat uit die antwoorde na vore kom, is dat die hoorders ' $n$ suiwer, verhelderende, toepaslike verklaring verlang met die fokus op alles wat aktueel is in hulle leef, belewings- en ervaringswêreld. Dit word wel deur verskillende hoorders anders bewoord, maar ek kan sê dat die antwoord van 75 persent van die hoorders die volgende woorde bevat: aktueel, daaglikse lewe, vandag, die huidige situasie, ens. Dit word ook beklemtoon dat predikers sterker moet toepas. Die O.T. en N.T. moet nie net verlede tyd bly nie.

In hierdie verband het die vraag by my opgekom of ons nie te sterk konsentreer op net een bepaalde preekvorm nie. Eers die verklaring as een grootheid en dan die toepassing as ' $n$ tweede grootheid, soms dualisties langs mekaar, soos die kop en die liggaam. Ek het dit nie teen hierdie vorm as vorm nie, wel as enigste vorm. Die Bybel gee geen duidelike voorskrif oor die vorm waarin 'n preek gegiet moet word nie. Wel bied die Heilige Skrif aanduidings dat „die Woord reg gesny moet word; dat dit soos voedsel is wat toeberei word" ens. Elke tyd het sy eie preekvorm. So weet ons uit die geskiedenis van leerprediking, ervaringsprediking, heilshistoriese prediking, ens.

$\mathrm{Ek}$ is oortuig dat die rigoristiese vorm: verklaring - toepassing nie die aangewese is vir ons tyd nie. (Vgl. later by die omskrywing van die hoorder). Daarom praat ek van toepaslike verklaring. Dit is nie soos kop en liggaam nie, maar soos are wat die liggaam deurvleg vanuit die hoofslagaar (d.w.s. vanuit die grondgedagte van die eks). In die bespreking kan ons hierop terugkom.

3.2.2. Nuwe gesigspunte. Die meeste hoorders verwag van 'n preek ook minstens één nuwe gesigspunt, voortvloeiend uit die eksegese. Hulle verlang nie net 'n blote oorvertelling van die geskiedenis wat in die teks staan nie.

3.2.3. Betrokkenheid. Die lidmaat verlang betrokkenheid by die preek. Hy verlang om as 'n ware van die galery afgebring te word en in die regbank gestel te word om daar sy beskuldiging en vryspraak aan te hoor. Hoe kan gepoog word om dit te bewerkstellig?

4.2.3.1. Deur die preek voluit te skrywe.

3.2.3.2. 'n Pakkende aanhef - en 'n slot wat "neersit".

3.2.3.3. Kort sinne, pasop vir byvoeglike naamwoorde en gebruik veral werkwoorde.

3.2.3.4. Deur simpatieke solidariteit uit te straal.

Die hoorder verwag dus allerleers suiwer, verhelderende, toepaslike verklaring, 'n nuwe gesigspunt en betrokkenheid. Daar- 
volgens beoordeel hulle ook die preke. Iemand het gestel dat hy in die lig 80 persent van die preke as misluk beskou.

3.3. Studie en voorbereiding. Hier is die vraag gestel: Kry $\mathrm{u}$ as hoorder die indruk dat die prediker gestudeer het en eerlik probeer om die teks te verklaar.

Een derde (16 uit 47) van die hoorders het beslis „Ja" geantwoord. Die swaartepunt $(2 / 3)$ in die antwoorde lê by die gekwalifiseerde $j a$ op hierdie vraag. Ja.. maar, of $J a \ldots$ soms, selde, feitlik of nooit. Ek haal hier direkte stellings aan van sommige van die 32 uit 47 lidmate: „Die dominee maak te veel staat op sy voordrag. Sommige dominees, veral die wat al langer in die bediening is, skep die indruk dat hulle lankal klaar gestudeer het. Ja die dominee maak erns met sy preke, maar soms ontstaan die erns eers op die preekstoel. Enigiets word onder 'n teks kwytgeraak. Die dominee preek die Bybel vol. Sommige lidmate het gesê: Die studie is oppervlakkig - so 'n preek kan ek ook gemaak het". Dit was die tendens by twee derde van die lidmate.

Dit was verder opvallend dat by die vraag: „Indien u sonder reserwe met predikante kan praat oor die prediking wat sou $u$ aan hulle sê?" - daarop het die grootste aantal ook geantwoord: meer studie.

Persoonlik meen ek dat ons hierdie "studie" nader moet omskryf. By implikasie blyk dit ook uit die vraelys wat die lidmate met "studie" bedoel. Hulle sê ook dat die prediker nie moet poog om die indruk te skep dat hy studeer het en dan die mense met teologiese vaktaal probeer mislei nie.

Onder studie moet juis nie ,geleerde preke" verstaan word nie, maar eenvoud. D.w.s. het die prediker so geworstel met sy teks (perikoop) dat die gordyn wat ons tyd skei van 2000 jaar gelede deursigtig word, só dat die kerugma kontemporêr is in die prediking.

\subsection{Heilshistories - Eksemplaries?}

Saam met bg. kwessie van die studie hang saam die antwoord op die vraag of die N.T. vanuit die O.T. belig word en of tot 'n gelykskakeling in situasies gekom word.

Die helfte van die antwoorde dui aan dat die N.T. wel uit die O.T. belig word. Die ander helfte het geantwoord dat hierdie beligting soms, selde en nooit geskied nie, m.a.w. dat dikwels 'n direkte gelykskakeling tussen die O.T. en N.T. en ons huidige situasie gemaak word.

Dit is 'n tweede saak wat ek graag sou wou beklemtoon met die oog op ons bespreking: eksemplaries/heilshistories.

Myns insiens is daar in die prediking wel plek vir die ,exempel” (vgl. Hebr. 12:1,2), maar eksemplarisme is 'n onding.

3.5. Indien ons lidmate sonder reserwe met ons as predikers sou praat, sal die hoofsaak die volgende wees in die volgorde van belangrikheid:

3.5.1. Bring die Woord na deeglike studie eenvoudig, verstaanbaar, toepaslik en direk - en onthou waar om ,amen" te sê. Wees 
konkreet en vermy filosofiese spekulasie - lg. is 'n sterk voorwaarde, veral by die jeug.

3.5.2. Bly deur herderlike bediening en betrokkenheid op hoogte met die probleem van die mens vandag en die lewensgevoel van vandag, die leefwêreld van die mens.

Die prediker moet meer kennis dra van die „oop lewe” en die leefwêreld van sy lidmate. (Vgl. verder aan).

3.5.3. Waak teen oordrewe sondeprediking. Moenie "dramaties" raak nie (veral jonger predikante) en praat in 'n natuurlike rustige geselstrant.

3.5.4. Moenie aanvaar dat al die mense vir wie jy preek ,soet" gelowiges is nie. Beskou baie van hulle as soekendes en worstelaars.

3.5.5. Die dominee moet nie 'n eier lê en wilde uitsprake maak oor dinge waarvan hy nie genoeg weet nie (bv. internasionale politiek).

3.5.6. Die dominee moet meer probleemgesentreerd preek en nie so lank draai op historiese agtergrond nie.

\section{Stofkeuse}

Hier is twee vrae betrek.

4.1. Hoedanig varieer die stofkeuse vir die prediking (word bv. afwisselend uit die O.T. en N.T. gepreek).

4.2. Maak die tekskeuse ' $n$ beplande of 'n lukraak indruk? Die meerderheid $(2 / 3)$ van die lidmate is tevrede dat daar goeie variasie is en ongeveer een derde meen dat die afwisseling redelik tot min is en dat die tekskeuse soms 'n lukraak indruk maak. Daar word meer gekonsentreer op sekere gedeeltes en ander word nagelaat bv. profetiese en eskatologiese stof. Die antwoorde dui daarop dat meer uit die N.T. as uit die O.T. gepreek word.

\section{Aktualiteit}

Ek meen dat dit produktief sal wees om hier by elke vraag stil te staan.

5.1. Watter fokus het die prediking wat $u$ hoor (fokus dit bv. net die kerklike lewe of persoonlike voorkeure van die prediker of word die hele linie van die geloofslewe in oënskou geneem). Vyf en vyftig persent van die lidmate meen dat die prediking wel in hoofsaak 'n ewewigtige fokus het. Opvallend is egter dat ook hier 'n gekwalifiseerde ewewigtigheid bedoel word. Die algemene tendens is dat die fokus van die prediking of te eng of te breed is. Te eng in die sin dat in die meeste gevalle sterk gefokus word op die kerklike lewe en persoonlike beklemtoninge van die prediker (bv. sending, bydraes, kerkbesoek) of te breed waar, soos iemand dit gestel het, die dominee 'n eier wil lê oor sake waarvan hy te min weet - bv. internasionale politiek, oliekwessies, ens. Iets wat sterk beklemtoon word is dat die prediking meer duidelikheid moet bring oor hoe 'n lidmaat sy beginsels gestalte moet gee in sy algemene leefwêreld, die sake- en sportwêreld. Hier volg 'n letterlike aanhaling om bv. stelling te 
bevestig. „Die predikant dink hom nie in in die lewe van die gewone lidmaat nie. Vir die gewone lidmaat is daar naas die kerk, ook nog 'n hele ander wêreld, sy werk, loopbaan, verenigings- en sosiale lewe. Die stryd van die lidmaat is om in dié wêreld sy lewe in te rig volgens die eise van die Woord. Die persoonlike voorkeure van die predikant is te sterk". Hy ry net 2 of 3 perdjies om die beurt.

5.2. Dieselfde lyn is ook waargeneem uit die antwoorde op die vraag: Hoedanig motiveer die preke $u$ en $u$ gesin vir $u$ geloofslewe in die week. Een-derde (16 uit 47) het geantwoord: goed, en twee-derde het geantwoord gemiddeld tot swak. Interessante motiverings is gebied: (1) Die prediker word soms meegesleur deur pessimisme a.g.v. probleemgevalle - dit vind neerslag in sy preke. (2) Sy prediking is te dogmaties ingestel - dit onderrig maar betrek my nie. (3) 'n Paar het geantwoord: Ek vind soms meer baat by my eie Skrifondersoek.

5.3. Op die vraag of die prediking 'n boodskap van hart tot hart inhou het 14 uit 47 onbevange ja geantwoord en 33 uit 47 het gewissel van: meestal tot selde. Die redes volgens die hoorders is dat die verstand meer bevredig word as die hart. Dieselfde tendens is waargeneem by die vraag of die prediking die lidmaat en sy gesin in sy differensiasie raak (man, vrou, kind). Drie en dertig uit 47 het geantwoord meestal tot nooit.

5.4. Ongeveer 50 persent van die hoorders bespeur meestal ' $n$ aanvoeling by die prediker vir die pastorale probleme van ons tyd. Die ander 50 persent het o.a. die volgende antwoorde gegee: (1) Die predikant weet nie genoeg van die alledaagse ,swak" kant van die lewe nie. (2) Die dominee lewe te beskut en staan te negatief teenoor probleme. (3) Sy belangstelling in ons probleme is slegs akademies en pligsvervullend. (4) Hy weet wel iets van ons probleme, maar sy indringing en hantering van die probleme faal. (5) Hy preek te min vir die strydende, soekende sondaar. (6) Die spanning van ons tyd het ook onder die predikante baie slagoffers, en dit maak hulle ongevoelig vir die mens van vandag.

Twee sake is vir my hier opvallend: (1) dat die klem gelê word op die feit dat die verstand meer bevredig word as die hart. (2) Dat dit skyn asof ons nie genoeg herderlik betrokke is by die mense vir wie ons preek nie.

Ons moet steeds in gedagte hou dat hierdie antwoorde kom van die "goeie" lidmate, die mense wat tweemaal per Sondag kerk toe kom.

As die lyn van herderlike betrokkenheid deurgetrek sou word na die mense wat eenmaal per Sondag die kerk besoek, dan lyk die beeld nog ongunstiger.

Hierop kan ons in die bespreking verder terugkom.

5.5. Die vernaamste probleme van ons tyd wat die hoorder in die prediking betrek wil sien is koudheid, liefdeloosheid, verval van norme en beginsels, onsekerheid, die Bybelse perspektief op seks (veral die jeug), op rykdom, die sinvraag, lewensmoegheid, miskenning van gesag. 
Ter wille van die geheue vat ek die groot probleme van vandag saam in 2 snitte.

5.5.1. Hoe kan ek my geloof konkreet beleef en daaraan gestalte gee in my lewe van elke dag.

5.5.2. Die probleem van relatiwisme - baie lidmate voel soms aan dat verskillende waarhede vandag langs mekaar bestaansreg het. Dit lei tot twyfel, skuld en spanning.

Die antwoorde op hierdie vrae word in die prediking gesoek. Ek wil dit tog duidelik stel:

5.6.1. Die mens van vandag se probleme is m.i. nie groter as die van alle eeue - van Paulus se tyd af nie. Die probleme is net veel meer andersoortig en genuanseerd en bestorm die lidmaat wat na ons luister met groter intensiteit.

5.6.2. Die mens van vandag en sy omstandighede is nooit norm vir die prediking nie. God se Woord is die norm. Maar die mens van vandag het volle reg om te verwag dat sy probleme betrek sal word in die prediking.

Wat is die lewensklimaat van vandag? In watter wêreld bevind die mens vir wie ons preek homself?

Enkele riglyne:

5.7.1. Die klem op alle vlakke word vandag geplaas op die dinamiese eerder as op die statiese. Die mens van vandag lewe in die meervoud. Daarom het hy 'n hekel aan die statiese institusionalisering.

Prakties gesê: Die lidmaat vandag vra nie: Wat sê die kerk nie? Hy vra: Wat sê God? Die klem word geplaas op socke eerder as op gearriveerdheid.

Daarom is daar vir my iets voor te sê om dialogies te preek, om die lidmaat se vrae te betrek. Die groot voorwaarde is net dat die prediker en lidmaat saam uitkom by: So sê die Here.

5.7.2. Die lidmaat, veral die jeug, is soms skokkend eerlik op 'n ru manier. Die antwoorde op sommige vraelyste dien as illustrasie van bg. stelling. Kan van hierdie konfronterende, direktheid nie meer in die prediking teregkom sonder om platvloers te raak nie.

5.7.3. Pessimisme het optimisme vervang.

5.7.4. Blote intellektualistiese antwoorde spreek die mens nie aan nie. 'n Eenvoudige, warm, opregte getuienis het vandag meer krag as ' $n$ intellektuele betoog. Daar is 'n byna fanatieke soeke na egtheid en warmte.

5.7.5. Die mens is ingestel op die onmiddellike, die konkrete, eerder as op die filosofies-bespiegelende. 'n Voorbeeld uit 'n gebed illustreer bg. „Seën die inrigting waar die toekomstige dienare van $\mathrm{u}$ Woord opgelei word vir hulle hoogsheilige roeping ..." Dit is omslagtig - bespiegelend. Die konkrete is: Seën die teologiese skool.

Ek beweer nie dat elke lidmaat wat na ons luister man vir man bg. eienskappe vertoon nie. Ek wil wel sê dat die lidmate vir wie ons preek blootgestel is aan bestraling vanuit hierdie lewensgevoel.

Ons kan verder in die bespreking hierop ingaan. 
5.7.6. In verband met bg. lewensgevoel is dit ook nie verbasend dat 35 uit 47 lidmate hulle uitgespreek het ten gunste van die dialogiese metode vir aktueler prediking nie. Dit beteken m.i. dat die prediker in sy preek ook vrae stel wat leef in die harte van sy hoorders, vrae wat veral in die herderlike bediening opgevang is. Die groot voorwaarde is net dat by die antwoord uit Gods Woord helder en duidelik uitgekom moet word. Mens moenie met vrae die hoorder in die lug laat hang nie. Hy kom juis om die antwoord te hoor. As die prediking hom nie die helder antwoord bied nie, waar moet hy dit kry? Christus se gesprekke en prediking was ook sterk dialogies. Vgl. die gesprek met die Samaritaanse vrou. Klassiek is ook die gesprek met Petrus: Simon, seun van Jona, het jy My lief? Dit is 'n fyn dialogiese nuansering tussen agapê en filos. Op die dialogiese vorm wil ek dus ja sê op een voorwaarde: God sê die laaste woord en $\mathrm{Hy}$ het die finale sê.

Diskussie oor die preek na die diens word deur sewe agstes van die hoorders as onprakties beskou en Bybelstudie kan aanvullend en nie plaasvervangend nie gebruik word.

5.7.7. Hoe kan die prediker die gevaar vermy om die hoorders in sy prediking aanstoot te gee deur 'n houding van ,afstand, heilig wees", ens.?

Die hoorders bied die volgende antwoorde.

5.8.1. Deur natuurlike optrede en 'n natuurlike manier van praat. Die man op die preekstoel en die man wat in die week in sy gemeente rondbeweeg moet een en dieselfde man wees.

5.8.2. Deur 'n begrip te hê vir menslike swakhede; deur solidariteit uit te straal en nie ' $n$ beeld by die hoorder te skep dat hy as dominee nie kan struikel in die geloof nie. Die dominee kan gerus ook maar erken dat hy nie die antwoorde op al die vrae ken nie.

5.8.3. Deur vir jouself te preek - op dié manier dat jy jou inleef in bv. die posisie van die sweiser, of professor of prokureur wat daar voor jou sit. Dus: deur nie vanuit jou referensiekader as prediker te preek nie, maar vanuit dié van die lidmaat. 'n Aanhaling: Die dominee kan dalk meer begrip hê as hy die probleme sien teen die agtergrond van hierdie tyd en ons omstandighede en nie teen die agtergrond van die Bybelse tyd nie.

\section{Formeel}

6.1. Op die vraag of die preek logies en as 'n afgeronde geheel gebring word het 15 uit 47 ja geantwoord en 32 uit 47 van meestal tot nooit. Die versoek daarby is: Moet asseblief nie alles of te veel oor én onderwerp in jou preek wil sê nie.

6.2. Taalgebruik: Die hoorders stel die volgende vereistes t.o.v. taalgebruik vir die prediking:

6.2.1. Eenvoudige spreektaal, duidelik, verstaanbaar en in gespreksvorm.

6.2.2. Die gebruik van beelde om te konkretiseer.

6.2.3. Dat clichés vermy moet word. Dit. is woorde of uitdrukkings 
waarvan die algemene betekenis nog duidelik is, maar die konkrete inhoud ontbreek: Bv. magte van die duisternis, genadeverkondiging, op die lippe lê, na die mening van die Gees ens. Ek kan eerlik sê dat die lidmate oor die algemeen tevrede is met die taal wat in die prediking gebruik word. Hier volg 'n paar aanhalings van uitdrukkings wat die hoorders hinder.

- Ek wens net dat predikante nie 'n „punt wil maak nie". - Hoekom moet 'n sieke altyd krank wees en hoekom moet altyd gespreek word en nie soms gepraat word nie?

- Woorde soos die volgende is hinderlik vir hoorders: hoog. konjunktuur, antagonisme, historie, ens.

'n Paar lidmate het gevra of ons nie bietjie kers wil opsteek by die kommunikasiekunde nie.

6.3. Predikantshoudinge wat afgekeur word.

Twaalf uit 47 hoorders het geantwoord dat plaaslik geen besondere predikantshoudinge is wat hulle afkeur nie. Vyf en dertig uit 47 word gehinder deur die volgende predikantshoudinge (letterlik aangehaal):

6.3.1. Gewigtigheid en vernaamheid, ekkerigheid en 'n oorsimpatieke kunsmatigheid.

6.3.2. Gebrek aan nederigheid. Bombasme, hoogdrawendheid en platheid.

6.3.3. Die dominee wat te hard of te sag preek en skreeu en fluister skerp afwissel.

6.3.4. Kunsmatige gebare.

6.3.5. Preekstem.

6.3.6. Gesigsuitdrukkings - te glimlaggend skep die indruk van iemand wat nooit kwaad kan word nie.

6.3.7. On rustige trippelgang op die preekstoel.

6.4. Tydsduur: Die ideale tydsduur vir 'n preek word beskou as 20 tot 25 minute.

6.5. Bevatlikheid: 'n Derde van die lidmate het geantwoord dat die prediking wel tot soms bevatlik is vir die kinders.

6.6. Allerlei adviese van hoorders aan predikers in volgorde:

6.6.1. Die inleiding moet pakkend wees en my betrek by die preck. Moenie die hele preek in die inleiding hou nie.

6.6.2. Groter herderlike betrokkenheid by die lidmate sal die prediking bevorder.

6.6.3. Moenie so preek dat die lidmate die gevoel kry dat hulle in die hemel bly en op die aarde loseer nie.

6.6.4. Ons geboue raak modern - maar baie preke bly stereotiep. Indien die Here 'n dominee roep van gemeente $A$ na gemeente $B$ behoort sy prediking nie dieselfde te bly nie, ook nie sy huisbesoek en katkisasie nie.

6.6.5. Predikante moenie aanvaar dat selfs professionele hoorders geskoolde teoloë is nie.

6.6.6. Iemand het opgemerk: In die Kategismuspreke is te min direkte verband tussen Heilige Skrif en Kategismus. Daarom is baie Kategismuspreke 'n soort dogmatieklesing en gaan die gerigtheid op die praktyk heel dikwels verlore. „Ook my twyfel, onkunde, onsekerheid, onverskilligheid en eensaamheid moet 
in die Kategismuspreek verwoord word". Preek uit al 3 belydenisskrifte.

6.6.7. Plaas meer klem ook op die emosie.

6.6.8. Moenie die probleme in die gemeente wil regpreek van die kansel af nie en moenie vir lidmate preek wat nie in die kerk is nie.

6.6.9. Meer aandag aan voordrag tydens opleiding.

Baie lidmate het hulle waardering betuig vir die geleentheid om sonder reserwe hulle mening te kan gee oor die prediking.

\section{Samevatting}

Ons het die lidmate se mening behandel oor die inhoud, stofkeuse, aktualiteit en formele aspekte van die preek. Wenke van hoorders is in berekening gebring. Die volgende vlakke is uitgelig met die oog op die bespreking:

7.1. Die kwessie van verklaring en toepassing of toepaslike verklaring.

7.2. Die kwessie van gesonde ,exempel” of eksemplarisme.

7.3. Die leefwêreld van ons lidmate, die omlyning van die moderne lewensgevoel, die herderlike betrokkenheid by die lidmate en die kwessie van dialogiese vorm in die prediking?

7.4. Ek wil 'n laaste besprekingspunt op die agenda plaas. Ons het geluister na 'n openhartige waardeskatting van ons prediking. Kan dit nou maar hier ophou of moet hierdie evaluering deurgetrek word na die plaaslike vlak waar ons preek, werk en beweeg? Ja seker, die ouderlinge hou toesig, maar die praktyk is dat hulle sal praat as die dominee ketter. Moet 'n kanaal nie gevind word waar ons eerlik die preke en optrede van die predikant, sê elke maand, onder oënskou neem en baie openhartig bespreek nie. Ons tyd vra daarvoor. 'n Bedieningskommissie uit die kerkraad en gemeente kan dit goedskiks behartig. Op alle vlakke word werk vandag geëvalueer - waarom nie by die predikant nie?

Nou weet ek ons as predikante is baie fyngevoelig vir kritiek en beleef dit soms as bedreiging - dit maak jou of kwaad of laat jou in jou dop kruip. Moet ons, predikers van die Evangelie, nie eerste wees om ons oop te stel vir welmenende opbouende kritiek wat kom in die gesindheid van Jesus Christus nie. Ons kan baie kritiek uitdeel - kan ons dit aanvaar?

Die feit dat ons in ' $n$ amp staan en die feit dat die Heilige Gees die prediking in sy diens gebruik en daarvoor toerus, is geen gerieflike wegkruipplek nie - dit bevestig juis die noodsaaklikheid om ons werk in oënskou te neem en eerlik daaroor te praat.

Juis omdat jy instrument is van die Heilige Gees!

C. J. H. Venter. 